\title{
THE IMPACT OF POPULATION AGING ON ENVIRONMENTAL QUALITY: DOES SOCIAL SECURITY MATTER?
}

\author{
Fatma SAFI* \\ Lobna BEN HASSEN**
}

\begin{abstract}
In this paper, longevity, social security and the environment are modeled in the context of the prominent two-overlapping-generations general-equilibrium model with rational expectations. The model is developed to examine the impact of population aging, in a pay-as-yougo (PAYG) financed defined contributions pension scheme, on the evolution of capital and environmental quality. Analytical outcomes are derived for the steady state by the method of comparative statics. We have shown, by analysing the effect of aging on environmental quality that the influence of social security appears when the value of longevity exceeds 0,4 . A transient regime is obtained by investigating the effect of longevity on capital accumulation at the point where the longevity is equal to 0,24 . We have proved that the increase in pensions benefits affect negatively the amplitude of the steady-state capital.
\end{abstract}

Keywords: Aging, environment, OLG model, social security, uncertain lifetimes

DOI: 10.53373/ VULS.2021.38.2.007

\section{Introduction}

The environment is usually viewed as a capital that is transmitted to coming generations however ensuring environmental sustainability is also essential to oneself future utility: nonetheless, environmental concern gives away some consideration for the future. Besides, population aging is one of the major factors influencing the way persons appreciate future. Clootens (2017) stated that a rational individual with high life span gives a bigger importance to the future and is more eager to sacrifice current well-being in preference to upcoming benefits. Consequently, if someone presumes to be alive longer he should be prepared to spend more in environmental abatement: a greater longevity makes individuals more concerned about next generations and their future selves. This argument exists in Ono and Maeda (2001) who bring in the notion of private abatement founded on longevity. Under a perfect annuitization hypothesis, Ono and Maeda (2002) demonstrate that a greater longevity will possibly raise growth and the quality of the environment. Additionally, the relationship between the social security and the quality of the environment has enticed significant emphasis. The environmental tax-financed social security reform was examined by Felder and Nieuwkoop (2000), Wendner (2001), and Ono (2005; 2007) and displayed that this reform makes the quality of the environment and well-being better. Rangel's (2003) and

\footnotetext{
* Department of Economics, Faculty of Economics and Management, University of Sfax, Street of Airport, km 4.5, LP 1088, Sfax 3018, Tunisia, fatma_safi@yahoo.fr.

** Faculty of Economics and Management, University of Sfax, Tunisia, lobna.benhassen@fsegs.rnu.tn.
} 
Liang and $\mathrm{Wu}$ (2013) study the relationship between social security and the quality of the environment in the political equilibrium and the competitive equilibrium respectively.

Our investigation is theoretical in nature. We revise the impacts of population aging through rising length of life on the environment, in an overlapping generations (OLG) model where a government offers a pay-as-you-go pensions, financed with a defined contribution scheme. Specifically, we would like to attack the role played by pension benefits on the steady-state level of capital and environmental quality in an aging economy. This constitutes our major contribution to the literature. To do so, we set up a simple two-period model where all decisions are taken by perfect forward-looking individuals who maximize a utility function whose arguments are consumption in first and second period and environmental quality in second period of life. Employing a logarithmic utility function and a Cobb-Douglas production function, we obtain ambiguous analytical outcomes. We carry out then a simulation of our model for the purpose of illustrating how this ambiguity straightens out for a certain set of parameter values.

Section 2 consists of the review of related studies. Section 3 depicts the economy's key features. Section 4 displays optimal choices and inter-temporal equilibriums. Section 5 explores the condition attributed to the existence of equilibriums. Section 6 centers on the comparative statics, and finally the last section rounds up the study with the conclusions.

\section{A review of the theoretical literature}

There exists two of the predominant analysis in the population aging. First one explores the impacts of population aging on the environment. The impact of aging on environmental sustainability was reported in many dynamic general equilibrium OLG models. Ono and Maeda (2001) and Ono (2005) consider two sides of high life expectancy which may exhibit contradictory impacts on the quality of the environment. First, high life expectancy can enhance an agents' concern about upcoming environmental preservation. Second, high life expectancy as a result of a lower population growth indicates that less aggregate damaging emissions can be caused by a decrease in demography. Ono and Maeda's (2001) outcomes recommend that the effect of greater longevity on the environment is determined by the shape of the utility function. Ono (2005) pays attention to how increased life expectancy and lower rate of population growth influence the quality of the environment and the environmental tax on firms.

Given that aging concurrently obliges the government to accord a higher importance to individuals 'consumption, by this means diminishing the tax rate; and a greater importance to utility gained from environmental quality, consequently rising the tax rate, at equilibrium the final impact of greater longevity on the environmental tax rate is null. The impact of greater life expectancy on the quality of the environment is strong and works through the effect of the annuity market on capital stock which influences pollution ejections and environmental expenditures. In addition, Ono (2005) notices that as elderly in an aging population grip high political weight and by hypothesis do not prefer the quality of the environment, demography growth negatively influences the environmental tax rate on firms. The two-way causality between longevity and environmental quality was explicitly modeled by Mariani et al. (2010). Key among their findings is that increases in individuals' lifespan in the third and final period of life heighten spending in the environmental and decrease consumption which degenerate the environmental quality. Besides, given the endogeneity of 
life expectancy, if it is influenced by the quality of the environment through a convexconcave function, the model contains multiple equilibriums which can explicate the existence of environmental poverty traps marked by poor environmental quality and high disease rate. Tubb (2011) presumes that people are taxed and that taxation earning may be invested on either environmental care or on elderly transfers. Longevity boosts the proportion of older population and subsequently boosts political tension for the public planner to lean the structure of public expenditure in support of a fund transfer to the older population. Given that young people envisage that increased life expectancy signifies a high return from such investment, Longevity may at the same time enlarge the young people's demand for environmental maintenance. Numerous contributions find a drop of physical and/or human capital accumulation when life expectancy reduces (Chakraborty (2004), Varvarigos (2010), Varvarigos (2013), Wang et al. (2015)). Multiple long-term equilibriums with poverty traps can be caused (Mariani et al. (2010), Varvarigos (2014)).

Second one considers the impacts of longevity on the social security program. Feldstein and Liebman (2002) displayed that the social security benefits are amplified quickly in society aging. Early researches on the theoretical solution to PAYG pension plan by Samuelson (1958) and Cass and Yaari (1966) supposed a stationary population. Within this frame of reference, the generational equivalence needed to sustain constant consumption streams to older population is considered as the equality of population growth rate and the market interest rate, which generally gives thought to the internal rate of return from PAYG pension plan. Various papers draw conclusions on how longevity is predisposed to boost the tax weight needed to support the social security system over a certain period of time and how the arising care expenditure might be alleviated via diverse social security system reforms. Heer and Irmen (2014) study the impact of social security reform on the endogenous growth rate. Because of higher life expectancy, labor supply may become rarer. Thus, firms have a higher enticement to spend on labo-augmenting technological modification. Conesa et al. (2016) investigates the capacity of tax incidence metrics to depict the extent of the impacts of policy reforms and the characteristics of the persons who benefit or take care of the cost of the reforms. The authors point out that these metrics work defectively in inspecting policies that lessen distortions and ameliorate efficiency. From Japanese micro data, Imrohoroğlu et al. (2016) employ estimates to simulate future paths of fiscal quantities. The authors advocate that lacking any modification in existing policies, Japan will persist to run significant pension and non pension deficits, and the debt-to-GDP ratio will persist to attain extraordinary peak, with interest payments on the debt becoming the largest and intensifying weight. Additional reductions in the birth rate in high-income countries will influence the social system and economy. Specifically, a low birth rate brings in labor market scarcities, and a pressure on tax and social security revenues, accompanied by negative impacts on pension systems (Heer et al. (2021)).

\section{The Economy}

The study is built on the prominent two-overlapping-generations model where there are a great number of agents living for two periods, youth and old age, at maximum, however may die at the beginning of the second period of life. Let $\pi \in(0,1)$ be the probability that an agent lives for two periods (longevity). Everyone is identical excluding differences in age. Each young agent takes aggregate savings and the tax rate as given. We suppose that every agent born at time $t$ works a fixed amount of time at wage $\omega_{t}$ during his young age. Some of this wage is taxed away by the government by a lump-sum tax $\tau_{t}$ to be shifted to the elderly. 
The rest is used for savings for old age $\left(s_{t}\right)$, private environmental abatement activities $\left(m_{t}\right)$ and for consumption $\left(c_{t}^{y}\right)$. Hence, we get:

$$
(1-\tau) \omega_{t}=c_{t}^{y}+s_{t}+m_{t} \text {. }
$$

At old age, the agent consumes the return on his savings and the transfer payment from the government. Hence the consumption at time $t+1$ of an old agent born at time $\mathrm{t}\left(c_{t}^{o}\right)$ is given by:

$$
c_{t+1}^{o}=\left[1+r_{t+1}\right] s_{t}+\eta_{t+1} .
$$

Agents are considered egoist. The utility of an agent born at time $t$ is characterized by the following function:

$$
U=\ln c_{t}^{y}+\pi \ln c_{t+1}^{o}+\ln Q_{t}+\pi \ln Q_{t+1}
$$

The utility function $U$ abides by the Inada-conditions.

The quality of the environment at time $t+1$, calculated by the environmental index $Q$, is ruined by consumption of the elderly at time $t$ and ameliorated by abatement spending, $m_{t}$. The environmental quality grows à la John and Pecchenino:

$$
Q_{t+1}=(1-\theta) Q_{t}-\beta\left(c_{t}^{y}+c_{t}^{o}\right)+\delta m_{t},
$$

where $Q_{t}$ defines environmental quality in period $t, m_{t}$ is private expenditure on environmental investment, $0 \leq \theta \leq 1$ is a parameter representing the degree of environmental persistence, $\beta>0$ denotes the externality consumption and $\delta>0$ measures how private expenditure transform into amelioration of $Q$.

\section{Inter-temporal equilibrium}

The individual saving can be in two kinds of assets: physical capital and an environmental valueless asset. Taking $\left\{\omega_{t}, r_{t+1}\right\}$ as given, the individual's program is to choose an allocation $\left\{c_{t}^{y}, c_{t+1}^{o}, s_{t}, m_{t}\right\}$ for the purpose of maximizing his utility in (3) subject to the budget constraints (1) and (2). This program gives the following first-order conditions:

$$
\begin{gathered}
\frac{1}{c_{t}^{y}}=\pi(\delta+\beta) \frac{1}{Q_{t+1}}, \\
{\left[1+r_{t+1}\right] \frac{1}{c_{t+1}^{o}}=\gamma \frac{1}{Q_{t+1}} .}
\end{gathered}
$$

Conventional equilibrium conditions on the factor markets and the goods market close the model. A standard neoclassical production function portrays the production per worker at time $t: y_{t}=f\left(k_{t}\right)=A k_{t}^{\alpha},\left(f^{\prime}(k) \equiv \frac{d f}{d k}>0, f^{\prime \prime} \equiv \frac{d^{2} f}{d^{2} k}<0\right)$ where $k_{t}$ is the capital-labor ratio, $A>0$ and $0<\alpha<1$. Assume that capital depreciates at the rate $\rho \in(0,1)$ during the production process, labor supply is exogenous and firms are competitive, factor market equilibrium is expressed by the marginal productivity conditions:

$$
\begin{aligned}
& \omega_{t}=f\left(k_{t}\right)-k_{t} f^{\prime}\left(k_{t}\right)=(1-\alpha) A k_{t}^{\alpha}, \\
& r_{t}=f^{\prime}\left(k_{t}\right)-\rho=\alpha A k_{t}^{\alpha-1}-\rho .
\end{aligned}
$$

Equilibrium on the goods market denotes that investment is equal to savings or in per worker terms

$$
s_{t}=k_{t+1} \text {. }
$$

The government conducts a defined contribution PAYG pension plan with a balanced budget. Therefore, labour income of the young agents is taxed, and the proceedings are spent to pay a pension for the retired. Thus, pension benefits are

$$
\eta_{t+1}=\omega_{t+1} \tau_{t+1} \text {. }
$$

Substituting equations (5), (7), (8), (9) and (10) lagged once into (1) yields 


$$
m_{t}=(1-\alpha) A k_{t}^{\alpha}-\eta_{t}-\frac{Q_{t+1}}{\pi(\delta+\beta)}-k_{t+1} .
$$

Substituting equations (8) and (9) into (2) yields

$$
c_{t+1}^{2}=\left[1+\alpha A k_{t}^{\alpha-1}-\rho\right] k_{t+1}+\eta_{t+1} \text {. }
$$

Substituting equations (5), (11) and (12) lagged once into (4) leads to

$$
\begin{aligned}
Q_{t+1}=(1-\theta) Q_{t} & -\beta\left[\frac{Q_{t+1}}{\pi(\delta+\beta)}+\pi\left[1+\alpha A k_{t}^{\alpha-1}-\rho\right] k_{t}+\eta_{t}\right] \\
& +\delta\left[(1-\alpha) A k_{t}^{\alpha}-\eta_{t}-\frac{Q_{t+1}}{\pi(\delta+\beta)}-k_{t+1}\right] .
\end{aligned}
$$

Furthermore, substituting equations (8) and (12) into (6) yields

$$
Q_{t+1}=\delta k_{t+1}+\frac{\delta \eta_{t+1}}{\left[1+\alpha A k_{t}^{\alpha-1}-\rho\right]} .
$$

Equations (13) and (14) depict the law of motion for the environment.

\section{Steady state}

Given that, in the steady state, all nominal and per-capita variables are constant, time subscripts are eliminated. Let $\hat{k}$ and $\hat{Q}$ designate steady state values. We can rewrite equations (13) and (14) as

$$
\begin{gathered}
\left(\frac{1+\theta \pi}{\pi}\right) \hat{Q}=-\beta\left[\pi\left[1+\alpha A \hat{k}^{\alpha-1}-\rho\right]+\eta\right] \\
+\delta\left[(1-\alpha) A \hat{k}^{\alpha}-\eta-\hat{k}\right], \\
\hat{Q}=\delta \hat{k}+\frac{\delta \eta}{\left[1+\alpha A \hat{k}^{\alpha-1}-\rho\right]} .
\end{gathered}
$$

The comparative static behavior of the steady state of this model is defined by the next proposition.

First, for the purpose of proving the stability of the steady-state equilibrium, we rewrite equations (13) and (14) as

$$
\begin{gathered}
(1+1 / \pi) Q_{t+1}-Q_{t}+\beta\left[\left[1+\alpha A k_{t}^{\alpha-1}-\rho\right] k_{t}+\eta_{t}\right] \\
-\delta\left[\left[(1-\alpha) A k_{t}^{\alpha}\right]-\eta_{t}-k_{t+1}\right]=0, \\
Q_{t+1}=\delta k_{t+1}+\frac{\delta \eta_{t+1}}{\left[1+\alpha A k_{t+1}^{\alpha-1}-\rho\right]},
\end{gathered}
$$

where $\alpha A k^{\alpha-1}>\rho$. Since (18) implicitly defines $Q_{t+1}$ as a function of $k_{t+1}$ only, rewrite it as

$$
Q_{t+1}=\Psi\left(k_{t+1}\right) .
$$

It is easy to confirm that $\Psi^{\prime}()>$.0 ; namely, a greater capital stock is correlated with better environmental quality. Let $\hat{k}$ and $\hat{Q}$ characterize steady state values. In steady state, the law of motion for the environment (17) can be rewritten as

$$
\hat{Q}=1 /(1+\theta)\left\{-\beta \hat{k}+\delta\left[\left[(1-\alpha) A \hat{k}^{\alpha}\right]-\eta-\hat{k}\right]\right\}=\Omega(\hat{k}) .
$$

In steady state, the first-order condition (19) is

$$
\hat{Q}=\Psi(\hat{k}) .
$$


To derive the condition of stability, substitute (19) and (19) lagged once into (17) to obtain the following first-order nonlinear difference equation in $k$ :

$$
\begin{gathered}
(1+1 / \pi) \Psi\left(k_{t+1}\right)-(1-\theta) \Psi\left(k_{t}\right)+\beta\left[\left[1+\left(\alpha A k_{t}^{\alpha-1}-\rho\right)\right] k_{t}+\eta_{t}\right] \\
-\delta\left[\left[(1-\alpha) A k_{t}^{\alpha}\right]-\eta_{t}-k_{t+1}\right]=0 .
\end{gathered}
$$

We can derive the stable condition by linearizing (20) around the steady state value $\hat{k}$ to obtain

$$
\begin{aligned}
& k_{t+1}-\hat{k} \\
& =\left[\frac{(1-\theta) \Psi^{\prime}-(\delta+\beta) \alpha A(\alpha-1) \hat{k}^{\alpha-1}-\rho-\beta\left[1+\alpha A \hat{k}^{\alpha-1}-\rho\right]}{(1+1 / \pi) \Psi^{\prime}-\delta}\right]\left(k_{t}\right. \\
& -\hat{k}) .
\end{aligned}
$$
$\Omega^{\prime}(\hat{k})$.

The coefficient on the right-hand side of (21) is less than one if and only if $\Psi^{\prime}(\hat{k})>$

\section{Comparative statics}

Totally differentiating (15) and (16), taking $\theta, \beta, \delta$ and $\rho$ as given, we have

$$
\begin{gathered}
{\left[\begin{array}{cc}
\frac{1+\theta \pi}{\pi} \quad & \beta \pi\left(1+\alpha A \hat{k}^{\alpha-1}-\rho\right)+(\delta+\beta \pi) \alpha A(\alpha-1) \hat{k}^{\alpha-1} \\
1+\alpha A \hat{k}^{\alpha-1}-\rho & \alpha A(\alpha-1) \hat{k}^{\alpha-2}-\delta\left(1+\alpha A \hat{k}^{\alpha-1}-\rho\right)
\end{array}\right]\left[\begin{array}{l}
d \hat{Q} \\
d \hat{k}
\end{array}\right]} \\
=\left[\begin{array}{cc}
\frac{\hat{Q}}{\pi^{2}}-\left(1+\alpha A \hat{k}^{\alpha-1}-\rho\right) \hat{k} \\
0
\end{array}\right] d \pi .
\end{gathered}
$$

Let $|D|=\frac{1+\theta \pi}{\pi}\left[\alpha A(\alpha-1) \hat{k}^{\alpha-2}-\delta\left(1+\alpha A \hat{k}^{\alpha-1}-\rho\right)\right]-\left(1+\alpha A \hat{k}^{\alpha-1}-\right.$

$\rho)\left[\beta \pi\left(1+\alpha A \hat{k}^{\alpha-1}-\rho\right)+(\delta+\beta \pi) \alpha A(\alpha-1) \hat{k}^{\alpha-1}\right]$ denotes the determinant, where $\alpha A(\alpha-1) \hat{k}^{\alpha-2}-\delta\left(1+\alpha A \hat{k}^{\alpha-1}-\rho\right)<0 . \quad$ Thus, $\beta \pi\left(1+\alpha A \hat{k}^{\alpha-1}-\rho\right)+(\delta+$ $\beta \pi) \alpha A(\alpha-1) \hat{k}^{\alpha-1} \geq 0$ is sufficient for $|D|<0$.

The effects of an increase in longevity on capital accumulation and environmental quality can be expressed as

$$
\begin{aligned}
& \frac{\partial \hat{k}}{\partial \pi}=\frac{1}{|D|}\left\{-\left(1+\alpha A \hat{k}^{\alpha-1}-\rho\right)\left[\frac{\hat{Q}}{\pi^{2}}-\left(1+\alpha A \hat{k}^{\alpha-1}-\rho\right) \hat{k}\right]\right\}, \\
& \frac{\partial \hat{Q}}{\partial \pi}=\frac{1}{|D|}\left\{\left[\alpha A(\alpha-1) \hat{k}^{\alpha-2}-\delta\left(1+\alpha A \hat{k}^{\alpha-1}-\rho\right)\right]\left[\frac{\hat{Q}}{\pi^{2}}-\left(1+\alpha A \hat{k}^{\alpha-1}-\rho\right) \hat{k}\right]\right\} .
\end{aligned}
$$

The sign of $\frac{\partial \hat{k}}{\partial \pi}$ and $\frac{\partial \hat{Q}}{\partial \pi}$ are ambiguous. For this reason, we will detect the impact of $\pi$ on $\hat{Q}$ and $\hat{k}$ by referring to the figures below. 


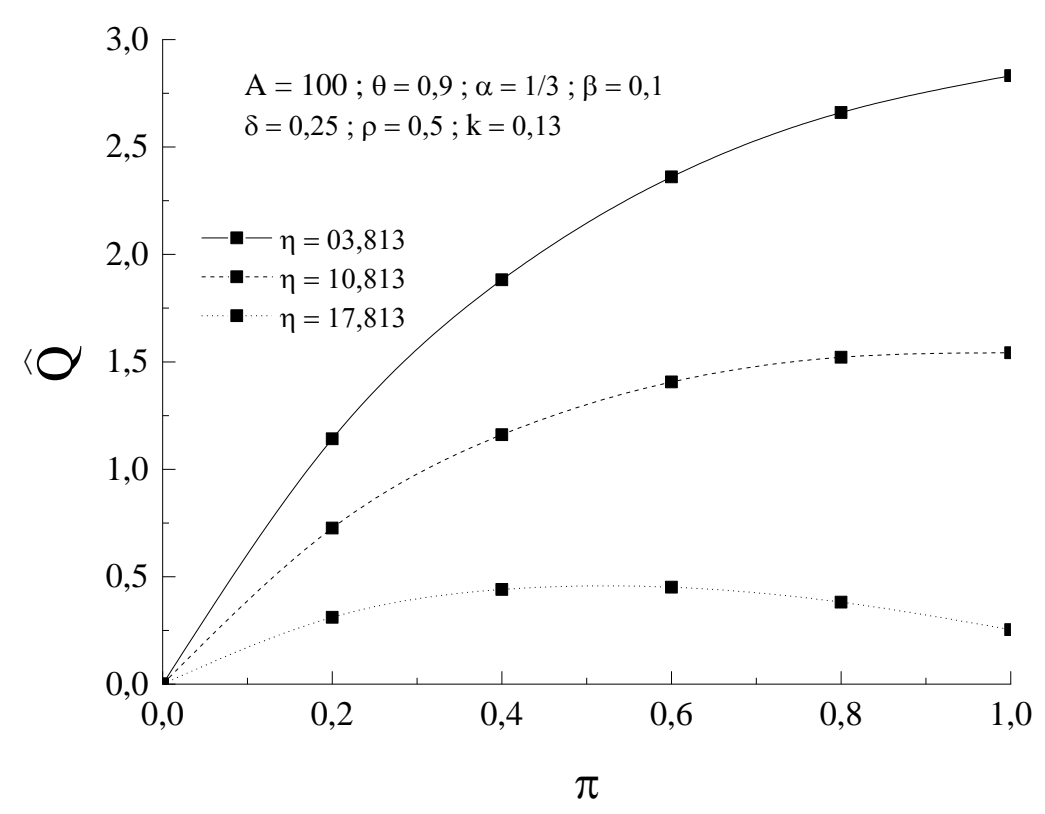

Fig.1. $\pi$ effects on steady-state environmental quality for different values of $\eta$

The Figure 1 illustrates the effect of longevity $\pi$ in the row $(0,1)$ on the steady-state environmental quality $\hat{Q}$ for different values of aggregate benefits paid to retired persons $\eta(\eta=03,813, \eta=10,813$ and $\eta=17,813)$. We find that $\hat{Q}$ increases rapidly as a function of $\pi$ without reaching the stationary regime when $\pi$ tends towards 1 . In the case of the intermediate value $\eta=10.813$, the steady-state environmental quality increases rapidly with the longevity beyond $\pi=0$. The main mechanism that explains the significant growth of $\hat{Q}$ is as follows. The care for environment appears to be deeper and larger among the young as it yields to outcomes over a long term view by reason of a longer remaining lifetime in which to appreciate better environmental quality. Thus, Greater longevity implies in intensification of environmental maintenance effort, which leads to better environmental quality. When longevity takes the value 0.4 , this rapid growth of $\hat{Q}$ asymptotically approaches a limit value and we observe the saturation effect $(\hat{Q}=1.55)$. Unlike the previous case and for $\eta=$ 17.813, $\hat{Q}$ increases slightly with $\pi$ from $\pi=0$ until $\pi=0.4$. Beyond $\pi=0.4$, this longevity has a negative influence on $\hat{Q}$ which decreases slightly and we observe the opposite effect of the first case where $\eta=03.813$. The economic intuition behind the decline in of the environmental quality $\hat{Q}$ is that: since lifetime rises, the number of the elderly expands too leading from one part to a growth in the pension benefits of the old people and from another part to an increase in the pension contribution rate of young population which efficiently removes income from young to old population. The old population's propensity to consume is superior to the young population's propensity. Thus, the average propensity to consume enhances. As a result, a rise in pension benefits due to a higher life expectancy reduces the steady state level of environmental quality. 


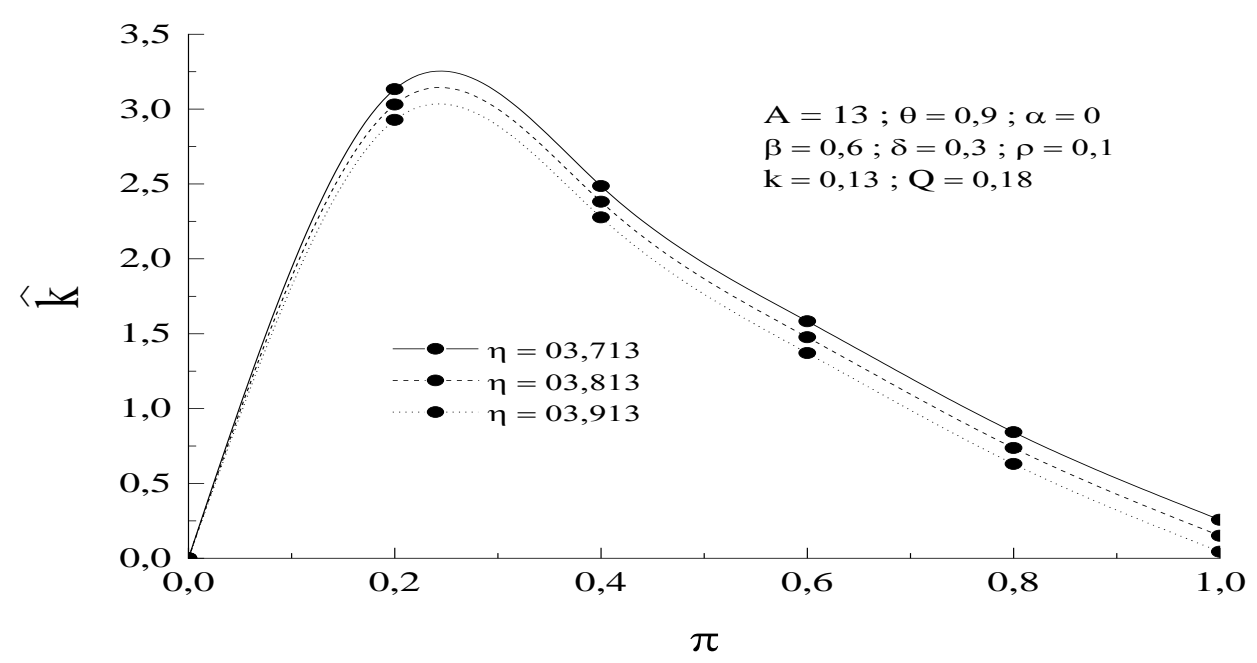

Fig. 2. $\pi$ effects on steady-state capital accumulation for different values of $\eta$

The influence of longevity on steady-state capital accumulation $\hat{k}$ is shown in Figure 2 for different values of aggregate benefits $\eta$. An identical behavior of $\hat{k}$ as a function of $\pi$ is detected and this independently of the considered value of $\eta$. The capital intensity grows very quickly from $\pi=\mathrm{o}$ to reach its maximum at $\pi=0.28$. Indeed, greater longevity may as well lead agents to modify their saving behaviour. With greater longevity, agents may save more throughout their first period of life, expecting that those savings will have to see them during a longer period when old. Thus, Greater longevity boosts precautionary savings which increases the capital without-regard-to pension benefits. Beyond $\pi=0.24, \hat{k}$ undergoes a dramatic decrease until $\pi=1$. As we said before, with higher life expectancy the average propensity to consume raises thus, the average propensity to save decreases. As a result, the steady state level of capital drops. For this reason, greater longevity is harmful to capital accumulation. Note that the maximum value of capital intensity $(\hat{k}=3,13)$ is obtained for $\eta=03.713$.

\section{Concluding Remarks}

In an overlapping-generations general-equilibrium framework, the role played by social security is examined when studying the effects of population aging on environmental quality and capital accumulation in a PAYG-financed public pension scheme. The results of the comparative static behavior of the steady state of our model exhibit ambiguous findings. I carry out then numerical simulations which show how a change in model's parameters affects the outcome.

Using this approach, we have shown, by studying first the impact of aging on environmental quality, that the influence of social security appears when the value of longevity exceeds 0,4 . Second, a transient regime is obtained by investigating the effect of longevity on capital accumulation at the point where the longevity is equal to 0.24 . We have 
proved that the increase in pensions benefits affect negatively the amplitude of the steadystate capital.

The present research is valuable because of two major reasons: first, to the best of our knowledge there are no previous theoretical studies investigating the intersection that relies between the environment, population aging and social security; second, the study displays potential for further implementations. One direction for future research is to extend the model to allow an analysis of a socially optimal steady-state allocation chosen by a central planner since the competitive equilibrium is dynamically inefficient in the presence of the consumption externalities in order to study the optimal taxation.

\section{References:}

1. Cass, D. \& M. E. Yaari (1966). Re-examination of the pure consumption loans model, Journal of Political Economy, 74, 353-367. 10.1086/259178

2. Chakraborty, S. (2004). Endogenous lifetime and economic growth. Journal of Economic Theory, 116 (1), 119-137. 10.1016/j.jet.2003.07.005

3. Clootens, N. (2017). Public debt, life expectancy, and the environment. Environmental Modeling and Assessment, 2 (3), 267. 10.1007/s10666-016-9535-1

4.Conesa, J.C, \& Garriga, C. (2016). Intergenerational policy and the measurement of tax incidence. European Economic Review, 83, 1-18. 10.1016/j.euroecorev.2015.10.009

5.Felder, S., \& Nieuwkoop, R. V. (2000). Using revenue from an energy tax to finance social security: A dynamic general equilibrium model for Switzerland. International Journal of Sustainable Development, 3, 136-145. 10.1504/IJSD.2000.001528

6. Feldstein, M., \& Liebman, J. B. (2002). Social security. In A. J. Auerbach, and M. Feldstein (Eds.), Handbook of public economics, 4, 2245-2324. Amsterdam: Elsevier Science.

7.Heer, B., \& Irmen, A., (2014). Population, pensions, and endogenous economic growth. Journal of Economic Dynamics and Control,46, 50-72. 10.1016/j.jedc.2014.06.012

8.Heer, B., \& Rohrbacher, S. (2021). Endogenous longevity and optimal tax progressivity, Journal of Health Economics, Elsevier. 79(C). 10.1016/j.jhealeco.2021.102515

9.Imrohoroğlu, S., Kitao, S., \& Yamada, T., (2016). Achieving fiscal balance in Japan. International Economic Review, 57(1), 117-154. 10.1111/iere.12150

10. John, A., \& Pecchenino, R. (1994). An overlapping generations model of growth and the environment. The Economic Journal, 104(427), 1393-1410. 10.4324/9781315257570-7

11. Liang \& Wu (2013). Is social security harmful to the environmental quality? International Journal of Economics and Finance. 5(12). 10.5539/ijef.v5n12p110

12. Mariani, F., Perez-Barahona, A., \& Raffin, N. (2010). Life expectancy and the environment. Journal of Economic Dynamics and Control, 34(4), 798-815 10.1016/j.jedc.2009.11.007

13. Ono, T., \& Maeda, Y. (2001). Is aging harmful to the environment? Environmental and Resource Economics, 20(2), 113-127. 23. 10.1023/A:1012676227797

14. Ono, T., \& Maeda, Y. (2002). Sustainable development in an aging economy. Environment and Development Economics, 7(01), 9- 22. 10.1017/S1355770X02000025

15. Ono, T. (2005). Environmental-tax-financed social security tax cuts and the double dividend. Finanz Archiv, 61, 178-200. 10.1628/0015221054553548

16. Ono, T. (2007). Growth and welfare effects on an environmental tax-based public pension reform. Japanese Economic Review, 58, 362-381. 10.1111/j.1468-5876.2007.00361.x 
17. Rangel, A. (2003). Forward and backward intergenerational goods: Why is social security good for the environment. American Economic Review, 93, 813-834. $10.1257 / 000282803322157106$

18. Samuelson, P. (1958). An exact consumption-loan model of interest with or without the social contrivance of money. Journal of Political Economy, 66, 467-482. $10.1086 / 258100$

19. Tubb, A. (2011). Does population ageing affect government environmental expenditure? Committee for Economic Development of Australia.

20..Varvarigos, D. (2010). Environmental degradation, longevity, and the dynamics of economic development. Environmental and Resource Economics, 46, 59-73. 10.1007/s10640-009-9334-0

21. Varvarigos, D., \& Zakaria, I.Z. (2013). Endogenous fertility in a growth model with public and private health expenditures. Journal of Population Economics, 26, 67-85. 10.1007/s00148-012-0412-1

22. .Varvarigos, D. (2014). Endogenous longevity and the joint dynamics of pollution and capital accumulation. Environment and Development Economics, 19, 393-416. 10.1017/S1355770X13000466

23. Wang M, Zhao J, \& Bhattacharyad J. (2015). Optimal health and environmental policies in a pollution-growth nexus. Journal of Environmental Economics and Management, 71, 160-179. 10.1016/j.jeem.2015.02.006

24. Wendner, R. (2001). An applied dynamic general equilibrium model of environmental tax reforms and pension policy. Journal of Policy Modeling, 23, 25-50. 10.1016/S01618938(00)00025-9 